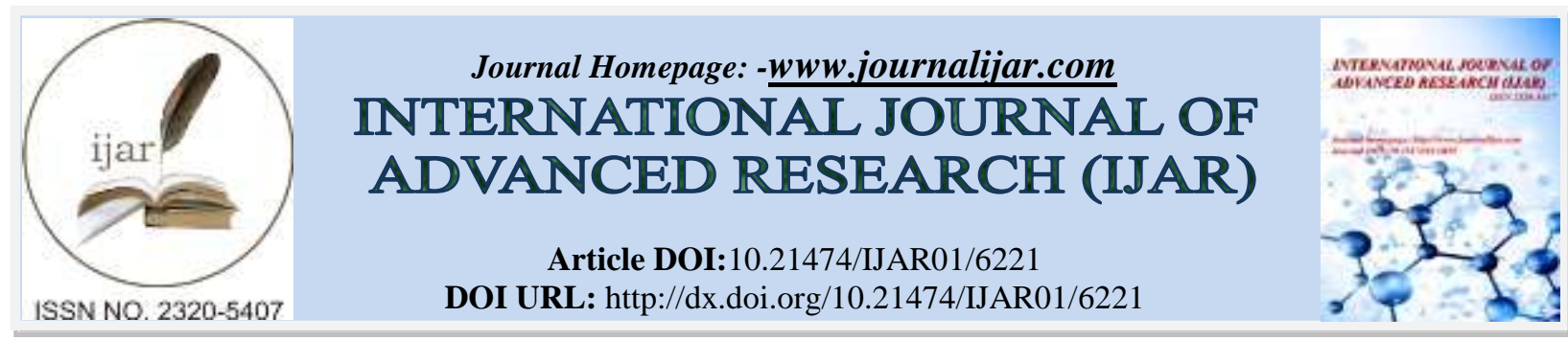

RESEARCH ARTICLE

\title{
REHABILITATION OF A HEMI-MAXILLECTOMY PATIENT WITH A CAST PARTIAL OBTURATOR PROSTHESIS - A CLINICAL REPORT.
}

Dr. Aprajita ${ }^{1}$, Dr. Atul Bhatnagar ${ }^{2}$,Dr. Kumari Deepika ${ }^{3}$ and Dr. Shankar singh ${ }^{4}$

1. Junior resident, Prosthodontic unit, Faculty of dental sciences, IMS, BHU, Varanasi, UP, India.

2. Professor, Prosthodontic unit, Faculty of dental sciences, IMS, BHU, Varanasi, UP, India.

3. Junior resident, Prosthodontic unit, Faculty of dental sciences, IMS, BHU, Varanasi, UP, India.

4. Junior resident,Oral and Maxillofacial unit, Faculty of dental sciences, IMS, BHU, Varanasi, UP, India.

\section{Manuscript Info}

(..........................

Manuscript History

Received: 05 November 2017

Final Accepted: 07 December 2017

Published: January 2018

Key words:-

Obturator, Cast- partial design, Aramany

Class- II, Hemi-maxillectomy.

\section{Abstract}

Prosthodontic rehabilitation of patient who have underwent maxillectomy surgery is a challenging task. Achieving optimum stability, retention and support are the major problems. An obturator with cast partial design is used to rehabilitate maxillectomy defect. The primary goals of the obturator prosthesis are to preserve the remaining teeth and tissues and to provide comfort, function, and aesthetics to the patients. This case report describes several steps of fabrication of a definitive obturator.

Copy Right, IJAR, 2018,. All rights reserved.

\section{Introduction:-}

The Maxillectomy defect may be congenital or acquired. The acquired defects may be due to either disease, trauma, pathological changes, radiation burns or due to surgical resection of tumors. These defects in the form of clefts, nasopalatal communication or opening into the antrum may vary from small opening to large defect that involve any portion of the hard \& soft palate, the alveolar ridges \& the nasal floor. ${ }^{1}$ Post-surgical maxillary defects result in difficulty in speech, impaired masticatory function \& nasal regurgitation. ${ }^{2,3,4}$ The primary goal of rehabilitating these defects include separation of oral \& nasal cavities to allow adequate mastication, deglutination, articulation \& the soft tissue support to restore acceptable esthetic to improve the quality of life of these individuals. ${ }^{5}$ There are many methods for rehabilitate these defects, one of them is obturator prosthesis.

\section{Case Report:-}

A 20 year old female patient reported with a chief complaint of difficulty in mastication \& speech in the department of prosthodontics. Her past medical history revealed that she had undergone left partial maxillectomy for neoplasm of left maxillary sinus 8 years back \& wearing surgical obturator and not undergone definitive obturator prosthesis. Intra-oral examination showed (Aramany, 1978) Class-II maxillectomy defect on the left maxilla, central incisor was retained on the defect side along with all teeth were present on the opposite side of the arch. (Fig1)

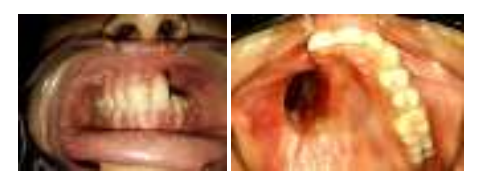

Fig1:- Pre-operative view of the hemimaxillectomy defect 
Treatment Plan:- Obturator with full palate major connector, 'I' bar retentive clasp on $21 \&$ embrasure clasp on 14 , $15 \& 17,18$ was planned. Treatment plan was well explained to the patient and a well informed consent was obtained. A preliminary impression was made with irreversible hydrocolloid using perforated stock tray, after blocking the defect area using sterilized wet gauge. The lower impression was also made at the same appointment using the same material. The primary casts were obtained from the impression. These casts were surveyed and the necessary mouth preparation was performed on the patient before making secondary impression. The final impression of the defect was made with addition silicone.(Fig2a) The master cast was poured in type IV stone. The defect was blocked out using wax. This will provide sufficient thickness of the acrylic material for the strength of the obturator. Cast partial denture design of the prosthesis was finalized and the framework was fabricated. Then the framework was tried in the patient's mouth to check for the fit. After that a denture base was fabricated and the jaw relation was recorded $\&$ articulated. The missing teeth were arranged and try in procedure was performed.(Fig2b) After wax-up, flasking was done. Following dewaxing procedure, heat cure resin was adapted into the defect area $\&$ mold space, the framework were placed back into their respective position on the cast and subjected to curing cycle. Following deflasking procedure, the prosthesis was trimmed, finished \& polished. The prosthesis was then inserted into the patient's mouth.(Fig3b) Post- insertion instructions were given and the patient's education regarding the use of prosthesis was done. The patient was re-called after 24 hours for the check up. Recall visits were also scheduled at 3 and 6 months for the evaluation of the prosthesis outcome.
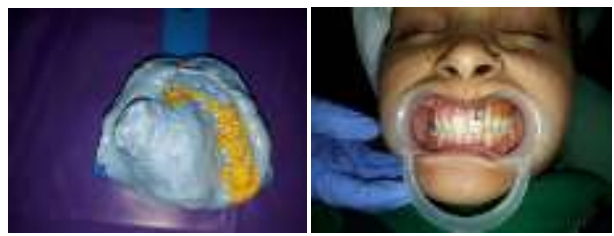

Fig2a:- Impression with addition silicone, Fig2b:-Try-in of the denture

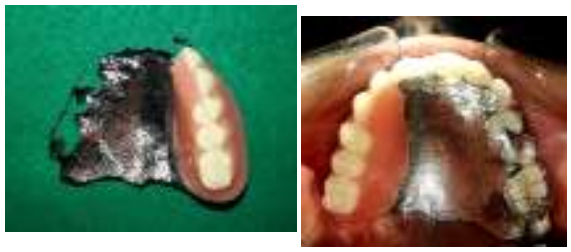

Fig3a:-Final processed cast partial denture, Fig3b:-Denture in place
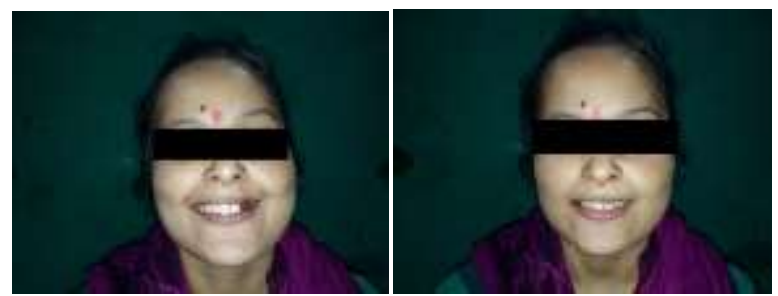

Fig4:- Smiling profile of the patient before and after installation of cast partial denture

\section{Discussion:-}

According to GPT-9-obturator is defined as a maxillofacial prosthesis used to close, cover, or maintain the integrity of the oral and nasal compartments resulting from a congenital, acquired, or developmental disease process, such as cancer, cleft palate, osteoradionecrosis of the palate; the prosthesis facilitates speech and deglutition by replacing those tissues lost because of the disease process and can, as a result, reduce nasal regurgitation and hypernasal speech, improve articulation, deglutition, and mastication; an obturator prosthesis is classified as surgical, interim, or definitive and reflects the intervention time period used in the maxillofacial rehabilitation of the patient; prosthodontic restoration of a defect often includes use of a surgical obturator, interim obturator, and definitive obturator. ${ }^{6}$ Prosthodontic rehabilitation of maxillary acquired defects could be classified into three stages of treatment. ${ }^{7}$ 
Immediate surgical obturator/plate: This type of appliance is constructed from an impression obtained prior to the operation and inserted at the time of surgery. Advantages of using immediate surgical plate includes provision of a stable matrix for the surgical packing, it can form a barrier between the oral cavity and wound during the initial healing, it enables the patient to speak and swallow more effectively. The major deficits and difficulties that occur after resection may have a psychological impact on the patient that may be reduced by the presence of the surgical plate. $^{7,8}$

Interim obturator: Two weeks after resection, the construction of interim obturator is advised .This type is totally acrylic incorporated with stainless steel wrought wire clasps engaging the remaining teeth for the purpose of retention. The patient should be seen every two weeks as the healing of the soft tissues in defect side exhibits more progress and lining materials can be placed. ${ }^{7,9}$

Definitive obturator: The definitive obturator should be constructed when the defect site is completely healed and is dimensionally stable. This may take from 3 to 6 months after surgery varying according to many factors e.g., prognosis of the tumor, size of the defect, healing progress and presence or absence of teeth. ${ }^{7,10}$ Designs for this type of obturators may vary based on the classification system of the defect. In this case as the patient did not report after installation of surgical obturator, interim obturator was not fabricated and treatment was directly switched to definitive cast partial prosthesis.

Abutments adjacent to distal extension maxillary resection sites are subjected to excessive rotational forces. Fixed splinting of some or all of the remaining teeth is indicated to provide dissipation of the stresses directed toward primary abutment teeth. Moreover, if the defect is small and the remaining teeth stable and unilaterally located ,intracoronal retainers might be considered. If the defect is large and some or all of the remaining teeth are weak, extracoronal retainers should be used. Guiding planes are made to resist vertical displacement of the obturator and disengagement of the retentive clasp arms in case if the remaining teeth are not parallel with the walls of the defect. $^{11}$ In the present situation, maximum distribution of support is achieved by incorporating more of the remaining teeth into the design of the framework and maximizing the use of occlusal and cingulum rests. Maximum extension onto the residual palate by using full palate major connector also increased the support for the prosthesis. As in this case, defect was not so extensive so there was no need for making hollow bulb obturator and the prosthesis was made in conventional manner. The basic principles of the design of removable partial dentures should be reviewed when designing the framework for an obturator. Major connectors should be rigid, occlusal rests should direct occlusal forces along the long axis of the teeth, guide planes should be designed to facilitate stability and direct retainers should provide bracing \& retention, these all should be within the physiological limits of the periodontal ligament, and maximum support should be gained from the residual soft tissues. ${ }^{11}$ Dimensional changes in tissue continue to occur for at least a year secondary to scar contracture and further organization of the wound. The prosthesis is rebased to compensate for these changes. Changes in the tissues supporting a maxillofacial prosthesis may be more rapid than in those of conventional prosthesis. Therefore, the occlusion and base adaptation must be re-evaluated frequently and corrected by selective grinding of the occlusion or rebasing of the prosthesis. $^{13,14}$

Quality of life of patients with maxillary defects could obviously be improved with the provision of a properly designed obturator. The prosthetic obturator can restore mastication, swallowing, esthetic particularly the midface, resonance and speech. Patients with maxillofacial defects who undergo rehabilitation can resume their social habits in the normal way. ${ }^{15}$

\section{Conclusion:-}

The present case report showed the prosthetic rehabilitation of an Aramany class II maxillary defect using a definitive obturator with cast partial design. A better masticatory efficiency, phonetics \& esthetics can be achieved with such cast partial removable prosthesis. Though it is difficult to improve the quality of life for hemimaxillectomy patients compared with patients with conventional prostheses, this can be achieved with skill, knowledge and experience of specialists. 


\section{References:-}

1. Beumer J, Curtis T, Marunick M. Maxillofacial rehabilitation: prosthodontic and surgical considerations. St Louis: IshiyakuEuroAmerica, Inc.; 1996:240-285.

2. Desjardins R. Obturator prosthesis design for acquired maxillary defects. J Prosthet Dent 1978; $39: 424$

3. Yoshida H, Furuya Y, Shimodaira K, Kanazawa T, Kataoka R, Takahashi K. Spectral characteristics of hypernasatity in maxillectomy patients. J Oral Rehab 2000;27(8):723-730.

4. Sykes LM, Wolfaardt JF, Sukha A. Prosthodontic rehabilitation of a patient with total avulsion of the maxilla (a clinical report). J Prosthet Dent 2002;88(4):362-366.

5. P. Cardelli, E. Bigelli , V. Vertucci , F. Balestra, M. Montani , S. De Carli , C. Arcuri. Palatal Obturators in patients after maxillectomy- A case report : Oral \&Implantology 2014 Jul-Sep; 7(3): 86-92.

6. Keith J. Ferro, Editor and Chairman, Glossary of Prosthodontic Terms Ninth Edition : J Prosthet Dent May 2017 ; Volume 117 Issue 5S

7. J. Beumer III, M.T. Marunick, S.J. Esposito (Eds.), Maxillofacial rehabilitation: prosthodontic and surgical management of cancer-related, acquired, and congenital defects of the head and neck (3rd ed.), Quintessence, Chandler Drive (2011), pp. 155-210

8. P. Andrades, O. Militsakh, M.M. Hanasono, J. Rieger, E.L. Rosenthal Current strategies in reconstruction of maxillectomy defects Arch Otolaryngol, 137 (2011), pp. 806-812

9. R.T. Frame, G.E. King. A surgical interim prosthesis J Prodthet Dent, 45 (1981), pp. 108-110

10. Chalian VA, Drane JB, Standish SM. Multidisciplinary practice. Baltimore: The Williams and Wilkins Co; 1971. Maxillofacial prosthetics; pp. 133-48.

11. Beumer III, Curtis TA, Firtell DN. St Louis, Toronto, London: The CV. Mosby Co; 1979. Maxillofacial rehabilitation. Prosthodontic and surgical considerations; pp. 188-243.

12. Buckner H. Construction of a denture with hollow obturator, lid, and soft acrylic lining. J Prosthet Dent. 1974;31:95-9.

13. Armany MA. Basic principles of obturator design for partially edentulous patients. Part II: Design principles. J Prosthet Dent. 1978;40:656-62.

14. Academy of denture prosthetics principles, concepts, and practices in prosthodontics. J Prosthet Dent. 1989;61:88-109.

15. R.E. Gillis Jr., W.M. Swenson, W.R. Laney. Psychological factors involved in maxillofacial prosthetics J Prodthet Dent, 41 (1979), pp. 183-188 